\title{
The development and practice of new quick-setting filling materials prepared by total industrial wastes
}

\author{
AX Wu University of Science and Technology Beijing, China \\ GZ Jiang University of Science and Technology Beijing, China \\ YM Wang University of Science and Technology Beijing, China
}

ZE Ruan University of Science and Technology Beijing, China

\begin{abstract}
Traditional paste filling materials adopt industrial solid wastes such as unclassified tailings and waste rocks as filling aggregates, but the binder used is dominantly commercial cement, which raises the filling cost. Hemihydrate phosphogypsum (HPG) is one of the main by-products of the phosphorus chemical industry, and the high-efficiency utilisation technology of HPG has been a problem worldwide. The potential gelling property of HPG is found in the laboratory at first. It is then modified by appropriate chemical and physical methods to produce new filling binder with the purpose of replacing cement completely. A lot of experiments show that the modified HPG (MHPG) has outstanding properties of quick setting (setting time less than 90 minutes), high early strength (UCS for three days more than $8 \mathrm{MPa}$ ) and good flowability (yield stress less than $50 \mathrm{~Pa}$ ). In addition, MHPG can bind different aggregates according to the filling needs to prepare a homogeneous, non-settling, and non-bleeding filling paste. In the past three years, two mines in Guizhou, China have adopted the underground paste backfill technology and surface open pit cemented filling technology based on MHPG paste materials. In practice, this new technology reduces the material cost by $30 \%$, increases the flow capacity by $50 \%$, and has a solid wastes rate of more than $98 \%$ compared to traditional methods.
\end{abstract}

Keywords: new quick-setting filling materials, total industrial wastes, underground paste backfill, open pit cemented filling

\section{Introduction}

Filling material is a composite material made of a binder, aggregates, and admixtures according to a certain formula. The binder is the key to improve the filling body performance and control the materials' cost. Portland cement (PO) is widely used in mine filling, but its expense accounts for more than $30 \%$ of the filling cost, which is unaffordable for some mines. In addition, PO used as a filling binder has two defects. One is that it has poor consolidation performance on fine aggregates such as tailings, sand, and high mud content materials. Second, due to its slow setting it may be not appropriate to the filling method requiring high early strength materials. In recent years, cheap and special mine binders have become one of the research hotspots in mine filling practice (Chen et al. 2021; Yin et al. 2020; Xie \& Chen 2016).

Increasing the free solid waste rate in the binder components is one of the keys to reduce the filling cost. Alkali-activated binder ( $A A B)$ made of industrial solid waste with pozzolanic activity, such as slag, fly ash, red mud, and alkaline agents has excellent late strength and can partially or completely replace PO. (Chen et al. 2021). However, the early strength of $A A B$ is often low, and large-scale standardised production is difficult due to its wide variety. Glue powder is a kind of $A A B$ with water-quenched slag as the main active ingredient (Yin et al. 2020). This binder is not only cheaper than PO, but suitable for various aggregates, including tailings, fly ash, coal gangue and sludge. It is widely used in many mines in China now, but the alkaline agent still accounts for a high proportion of the components, so more advanced cost control technology should be focused on. 
With the progress of large-scale mechanised production, the mining-filling cycle period is shortened. In this case, the early strength of a filling body must be improved to ensure the safety of underground operation and improve the ore recovery efficiency. The high water quick-setting material is a new binder composed of aluminate or sulfoaluminate, lime, gypsum, various additives, etc, known for high volumetric water content (more than 90\%), rapid setting (within 20 minutes), and high early strength (strength for one day more than 3.0 MPa) (Xie \& Chen 2016). It was widely applied to the roadway support in coal mines in the early years, but due to the scarce raw materials, high material cost, and high production requirements, only a few mines still use it now. The common measures to improve the early strength of binders are to add early strength agents or use high-efficiency alkali activators, which will undoubtedly increase production cost. At present, the development of low-cost, early-strength filling binders is still a general concern.

Hemihydrate phosphogypsum (HPG), the main by-product in the hemihydrate-wet process phosphoric acid production, is common in Guizhou, Guangxi, and Sichuan, China. HPG is recognised as industrial solid waste with difficult exploitation, costly utilisation, and low productivity due to it containing harmful impurities such as phosphorus acid, fluorine, and organics (Jiang et al. 2018). Traditionally, it is deposited directly on the surface, not only taking up a land footprint but also causing dust and water pollution (Tayibi et al. 2009). In 2015, our group took the lead in developing a new quick-setting total industrial wastes filling material (TQS-FM) based on HGP, which was characterised by quick setting, high early strength, and total industrial wastes (Wu et al. 2017b). In the past five years, based on the reproducible laboratory test results and multiple industrial verification tests, TQS-FM has been successfully applied to underground goaf treatment and open pit restoration.

\section{TQS-FM development}

\subsection{Physical and chemical characteristics of raw materials}

HPG, modifier, and unclassified tailings are used in this work. The HPG and tailings are taken from a phosphate fertiliser plant in Guizhou, China, and then dried in an oven. The modifier is a self-developed powdery alkaline additive, which is used to activate the gelling activity of HPG. Chemical methods and X-ray fluorescence spectroscopy (XRF), X-ray diffraction (XRD), and laser particle size analyser (LPSA) are used respectively to study the chemical composition, mineral composition, and particle size distribution of raw materials, as shown in Table 1 and Figure 1. HPG is mainly composed of metastable hemihydrate gypsum $(H G)$, which can undergo the hydration reaction (Equation 1) to generate dihydrate gypsum (DG). However, at the same time, $\mathrm{P}_{2} \mathrm{O}_{5}$ will combine with $\mathrm{Ca}^{2+}$ to form $\mathrm{Ca}_{3}\left(\mathrm{PO}_{4}\right)_{2}$ coatings (Equation 2). These coatings can hinder the dissolution of HG particles, further leading to increased setting times and the HPG activity deteriorating greatly (Singh 2005). The $d_{v} 50,-20 \mu \mathrm{m}$ particles content and uneven coefficient $C_{\mathrm{u}}$ of original HPG (OHPG) is $77.2 \mu \mathrm{m}, 8.66 \%$, and 3.23 respectively, so it is considered a coarse poor-graded material. The tailings without acidic impurities is mainly composed of dolomite, and belongs to fine well-graded material according to the results of $d_{v} 50,-20 \mu \mathrm{m}$ and $C_{\mathrm{u}}$ being $35.7 \mu \mathrm{m}, 42.63 \%, 13.41$ respectively.

Table 1 Chemical compositions of HPG and tailings (wt\%)

\begin{tabular}{|c|c|c|c|c|c|c|c|}
\hline Materials & $\mathrm{CaO}$ & $\mathrm{SO}_{3}$ & $\mathrm{Al}_{2} \mathrm{O}_{3}$ & $\mathrm{SiO}_{2}$ & Soluble $\mathrm{P}_{2} \mathrm{O}_{5}$ & Soluble F- & $\mathrm{pH}$ \\
\hline HPG & 45.13 & 46.01 & 0.57 & 5.22 & 0.59 & 0.39 & 3.69 \\
\hline Tailings & 34.44 & 0.82 & 0.38 & 2.59 & - & - & 6.78 \\
\hline
\end{tabular}




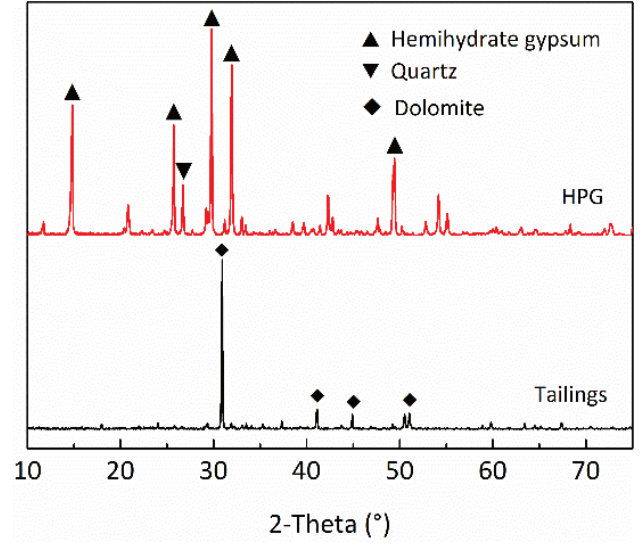

(a)

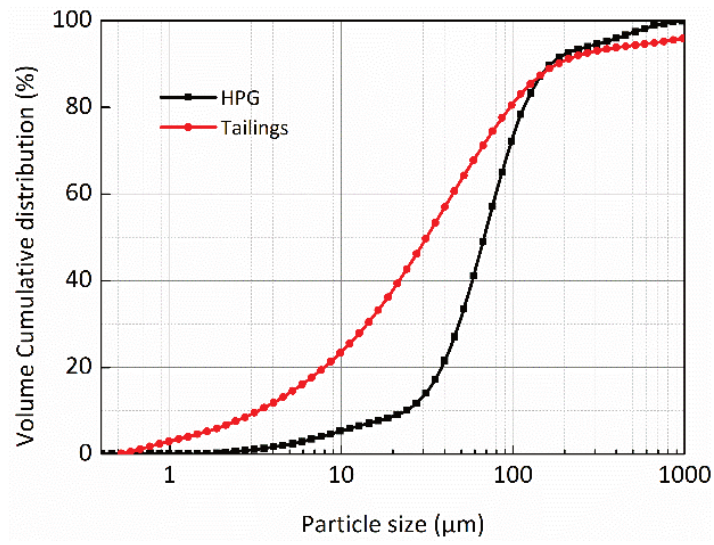

(b)

Figure 1 XRD and LPSA results of HPG and tailings. (a) Mineral composition; (b) Particle size distribution

\subsection{New quick-setting total industrial wastes filling binder (TQS-FB)}

As shown in Figure 2, the initial setting time of unmodified OHPG is more than 17 hours, and its compressive strength curing for three days $\left(\mathrm{UCS}_{3 \mathrm{~d}}\right)$ is only $0.1 \mathrm{MPa}$. Previous studies have shown that OHPG particles present multi-angular polycrystalline with low sphericity morphology (Jiang et al. 2018). This special shape increases the frictional resistance between particles exponentially, further leading to the OHPG slurry fluidity worsening, manifested as the standard consistency water demand of up to $60 \%$, and transportable mass concentration (C) less than $65 \%$. In addition, due to the lack of $-20 \mu \mathrm{m}$ particles, the water retention of OHPG slurry is poor, and the bleeding rate is still up to $13.1 \%$ at the maximum concentration of $65 \%$.

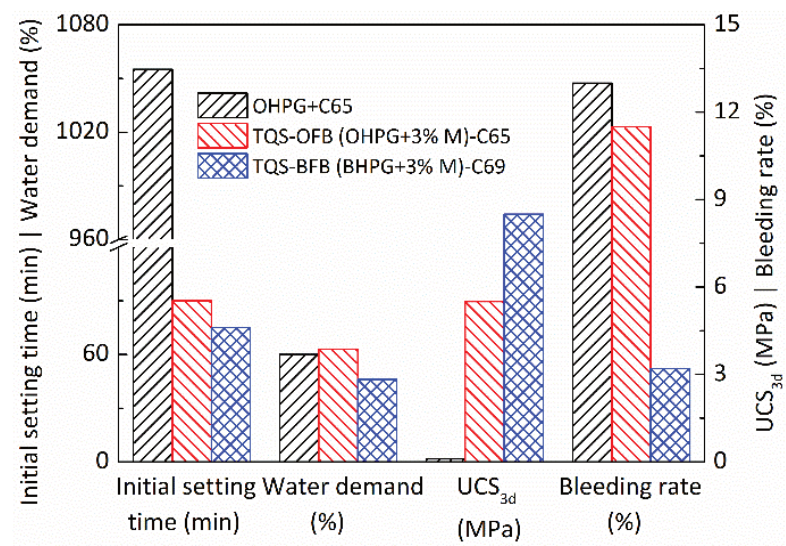

Figure 2 Primary filling performance of TQS-FB

When the $3 \%$ modifier (M) is added, the HPG activity is significantly improved; the initial setting time drops to $90 \mathrm{~min}$, and $\mathrm{UCS}_{3 \mathrm{~d}}$ soars to $6.5 \mathrm{MPa}$. From Equations 3, 4, and 5, it can be seen that the modifier can convert preferentially $\mathrm{P}_{2} \mathrm{O}_{5}$ and $\mathrm{F}^{-}$into insoluble precipitates, which avoids the adverse effects of $\mathrm{Ca}_{3}\left(\mathrm{PO}_{4}\right)_{2}$ coatings on the hydration process. With the accelerated hydration of TQS-FB composed of OHPG (TQS-OFB), the chemisorption between particles is enhanced, resulting in a decrease in bleeding rate and a slight increase in water demand.

$$
\begin{gathered}
\mathrm{P}_{2} \mathrm{O}_{5}+3 \mathrm{H}_{2} \mathrm{O} \rightarrow 2 \mathrm{H}_{3} \mathrm{PO}_{4} \\
x y \mathrm{H}_{3} \mathrm{PO}_{4}+n M \rightarrow x M_{n / x}\left(\mathrm{PO}_{4}\right)_{y} \downarrow+3 x y / 2 \mathrm{H}_{2} \mathrm{O} \\
x \mathrm{~F}^{-}+n M \rightarrow M_{n} F_{x} \downarrow
\end{gathered}
$$


The HPG specific surface area increases from 102.66 to $288.15 \mathrm{~m}^{2} / \mathrm{kg}$ after ball milling treatment. Figure 2 shows that the ball milling HPG (BHPG) has better fluidity than OHPG, manifested as a significant decrease in water demand. At the same time, the water retention of BHPG is greatly improved, and its bleeding rate decreases to less than $5 \%$ when the concentration is $69 \%$. More importantly, the ball milling treatment not only accelerates the TQS-FB composed of BHPG (TQS-BFB) hydration reaction, but also improves the UCS Ud $_{3 \mathrm{~d}}$ of the filling body. On the one hand, this is because of the maximum transportable concentration of TQS-BFB increasing to more than $69 \%$. On the other hand, the broken HPG polycrystalline makes the modifier mixed with $\mathrm{P}_{2} \mathrm{O}_{5}$ and $\mathrm{F}^{-}$more full, causing the modification effect to enhance.

\subsection{Quick-setting tailings filling material}

TQS-FB is characterised by quick setting and high early strength, and its cost is only five yuan/t, which fills the gap of the low-cost, early-strength filling binder. In addition, TQS-FB is suitable for various aggregates including traditional unclassified tailings and artificial sands, and uncommon dihydrate phosphogypsum without gelling activity. In this work, TQS-OFB and TQS-BFB are used to bind phosphorus tailings respectively, and the static fluidity, bleeding rate, initial setting time, and $U C S_{3 d}$ of the filling material are shown in Figure 3 . As shown, TQS-OFB tailings slurry with tailings content of $100 \%$ (T100) and the maximum transportable concentration of $69 \%$ (C69) has a bleeding rate of $8.7 \%$. The segregation problem cannot be ignored at this time. In contrast, the bleeding rate of TQS-BFB tailings slurry with the formulas of T100C71 and T200C73 is less than $5 \%$. In this case, the anti-segregation of the slurry is significantly improved and can meet the requirements for the underground paste backfill (Wu et al. 2017a).

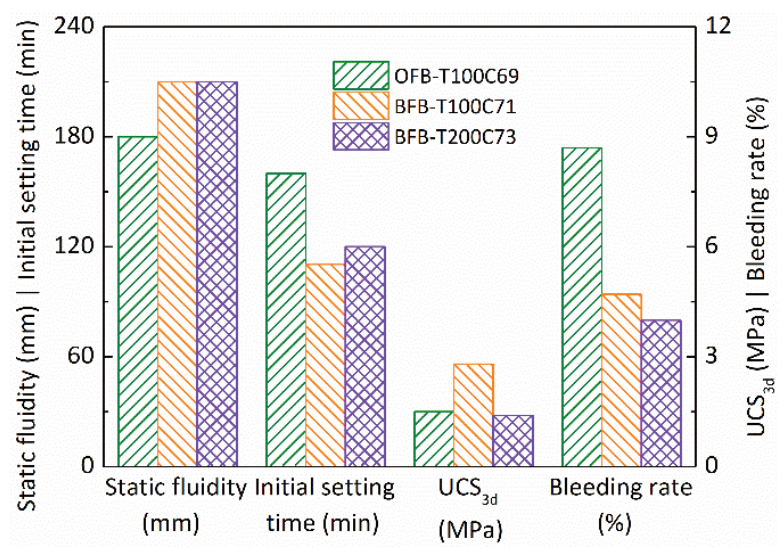

Figure 3 Primary filling performance of TQS-OFB and TQS-BFB tailings filling materials

Under the start-up flow conditions, the static fluidity of OFB tailings slurry is significantly worse than that of BFB tailings paste, which agrees with the stress overshoot phenomenon (Jiang et al. 2019) in the low shear rate region in Figure 4. The OFB tailings slurry has a stronger thixotropy than BFB tailings paste according to the closed-loop area of the rheological curve, which is because the former has a tighter flocs network before thixotropy under the effect of unique particle morphology. The fitting analysis results of downward rheological curves show that the curve segment with a shear rate of less than $100 \mathrm{~s}^{-1}$ is in line with the Bingham model. As the shear rate continues to increase, the curve has the characteristic of shear thickening, which matches the Herschel-Bulkley model better. The shear rate during pipe transportation is generally within $120 \mathrm{~s}^{-1}$, so the rheological parameters are obtained by using the Bingham model to fit the downward curve segment within a shear rate of $100 \mathrm{~s}^{-1}$. These rheological parameters reflect the fluid flow characteristics after thixotropy, that is, during the stable flow process after the start-up. According to the results of yield stress and plastic viscosity in Figure 4, the flow resistance of OFB tailings slurry is obviously less than that of BFB paste. This is because the shearing force reduces the HPG particles' friction by decomposing the polycrystalline structures. 


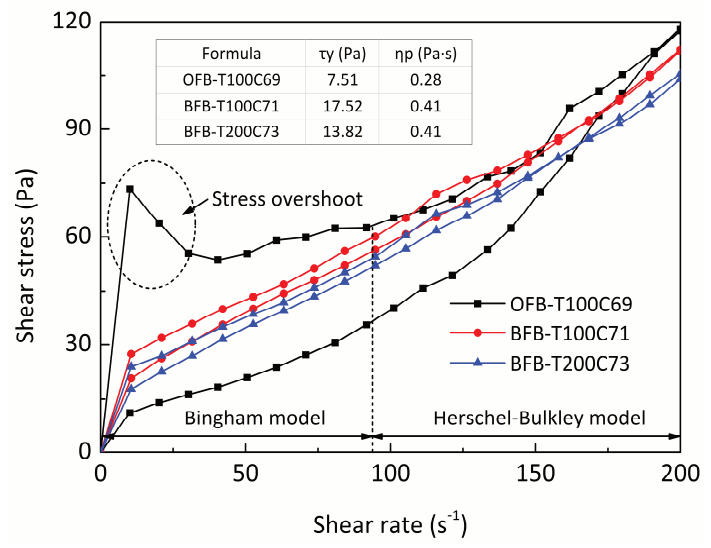

Figure 4 Rheological curves of TQS-OFB and TQS-BFB tailings filling slurry

The initial setting time of both OFB and BFB tailings materials is less than 180 min, inheriting the characteristics of quick setting and high early strength of this new binder. Considering the homogeneity of slurry and the strength of filling body, it can be concluded that the OFB tailings material is suitable for the working environment of simple transportation pipelines and a continuous and stable operation system. For the one-step subsequent filling, its tailings content should be $100 \%$ or less. BFB tailings material is suitable for various working environments. For example, the layered cemented filling should choose the formula of T100C71, and the one-step subsequent filling should consider the formula of T200C73.

\section{TQS-FM applied to underground goaf treatment}

\subsection{Background}

Most phosphate mines in Guizhou, China adopt the extensive open stope mining method. However, due to the low-profit rate of phosphate ore, these mines are often unable to afford the relatively high filling expenses, resulting in a large number of underground goafs not being treated. With the extension of the service life, some of the remaining goafs collapse gradually, which not only seriously threatens the safety of underground workers, but also has caused a series of geological disasters, such as surface collapse, mountain cracking, and landslides (Figure 5). In addition, Guizhou is one of the provinces rich in water resources in China. Whether the quality of surrounding water affected by the filling process can meet the strict local water protection policy should also be investigated further.

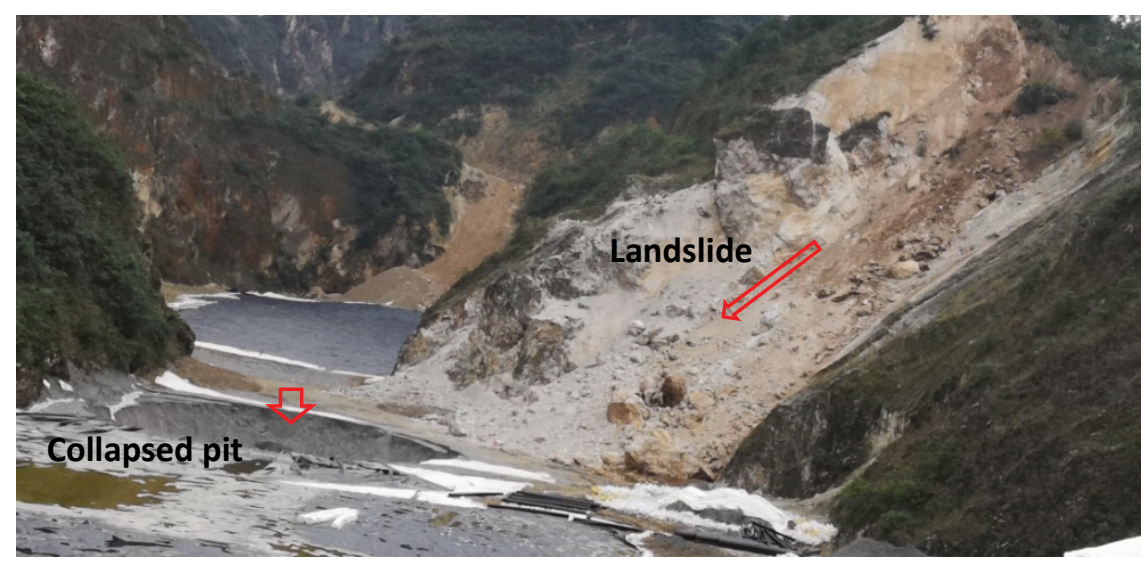

Figure 5 Collapsed pit and landslide caused by goaf collapse 


\subsection{Key features}

\subsubsection{Preparation of BFB tailings paste}

BFB is used as a binder to prepare filling paste according to the formula of tailings content of $200 \%$ and concentration of $73 \%$. The preparation station for this tailings paste can be seen in Figure 6 . Tailings with a moisture content of about $13 \%$ is usually disposed of by a dry discharge method. To solve the problems of slow feeding and easy compaction of wet tailings, a wrapper is installed in the bin wall, and HDPE overlay is covered on the inner surface of the bin. The feeding precision of the modifier determines the BFB work performance. A two-stage screw feeding and metering system is designed. The first large screw feeder can buffer the feeding shock and temporarily store the modifier. The second small screw feeder measures the modifier weight accurately, with a feeding error within $1 \%$. In addition, a two-stage mixing system is adopted to improve the paste mixing effect. The system adopts a double-shaft horizontal mixer in the first stage, and a single-shaft vertical mixer with a temporary storage design is used in the second stage. Finally, the prepared paste is transported to the goaf through a plunger pump with a flow rate of $60 \mathrm{~m}^{3} / \mathrm{h}$ and a pipeline.

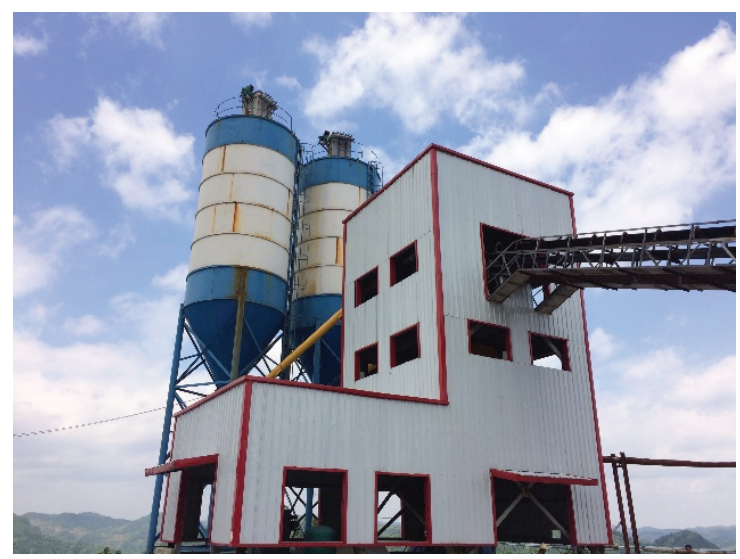

\section{Figure 6 First TQS-FM paste preparation station}

\subsubsection{One-time, single-point continuous filling}

Due to the characteristics of the quick setting of BFB tailings paste, the lateral pressure of filling retaining wall rises slowly. Therefore, it is not necessary to consider the multiple filling the early stage under the condition of reasonable wall design. At the same time, the paste has the characteristics of a small shrinkage rate and good flow leveling, which can ensure that the designed filling height can be realised by one-time, single-point continuous filling. The retaining wall is built with cement mortar and bricks, and its thickness $b$ can be determined according to Equation 6:

$$
b=\frac{B q_{\max }+\int_{0}^{H} \gamma_{p} h \mathrm{~d} h}{[\tau] \cdot B+\gamma_{w} H B \mu}
$$

where:
$B \quad=$ retaining wall width, $\mathrm{m}$.
$H \quad=$ filling height within the initial setting time, $\mathrm{m}$.
$q_{\max }=$ pressure value at the bottom of the retaining wall, $\mathrm{MPa}$.
$\gamma_{\mathrm{p}}, \gamma_{\mathrm{w}}=$ bulk density of paste and retaining wall respectively, $\mathrm{kN} / \mathrm{m}^{3}$.
$[\tau]=$ maximum shear strength of the wall, $\mathrm{MPa}$.
$\mu=$ friction coefficient of masonry materials, 0.6. 
The calculated $b$ should be greater than $0.0976 \mathrm{~m}$, so a single-layer brick wall is selected. Figure 7 shows that specially designed water filter holes are reserved in the wall to provide access for the leaching water in the goaf.

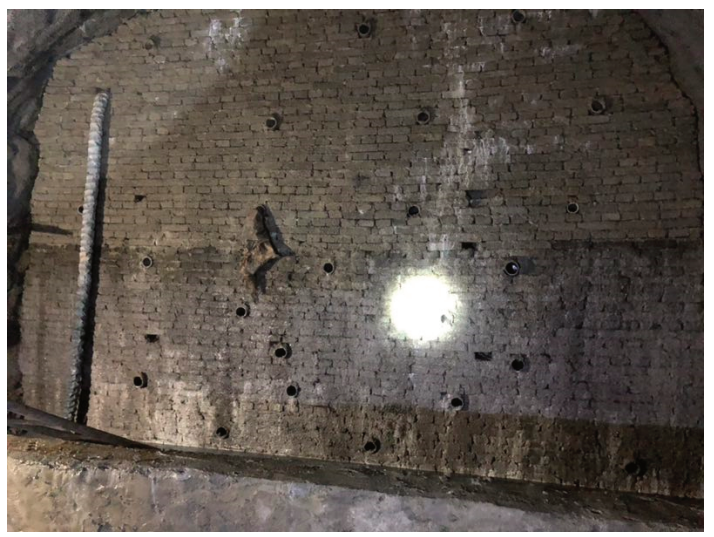

Figure 7 Single-layer brick filling retaining wall and water filter holes

\subsubsection{Comprehensive environmental impact assessment methods}

The toxicity of backfill, harmful gases, groundwater, and surface water quality in the area affected by the filling process are tested. We have established a thorough monitoring programme to comprehensively evaluate the impact of the new filling material on the surrounding environment, finally formulating the enterprise standard of TQS-FM filling technology.

\subsection{Application performance}

The early strength of filling body is high, manifested as UCS Ud $_{1 \mathrm{~d}}$ more than $1 \mathrm{MPa}$ and UCS $\mathrm{UC}_{3 \mathrm{~d}}$ about $1.5 \mathrm{MPa}$, which meets the requirements of one-step subsequent filling. The cost of new filling material is only 33.92 yuan $/ \mathrm{m}^{3}, 30-50 \%$ lower than that of traditional cement tailings material with the same strength. The TQS-FM paste with a shrinkage rate of $1.92 \%$ and a surface slope of $3.25 \%$ has good fluidity and strong segregation resistance (Figure 8). The one-time, single-point continuous filling can reach the designed filling height, and the retaining wall has no sign of instability during the filling process. Comprehensive environmental impact assessment results show that TQS-FM has no adverse effects on the environment, and it has been actively advocated as a model by the local government. Firstly, the filling body is classified as Class I non-hazardous solid waste according to the Chinese standard GB 18599-2001. Secondly, no harmful gases are detected during the filling process. Finally, according to the Chinese standard GB/T14848-93 and GB 3838-2002, both groundwater and surface water around the filling area can meet the Class III water quality requirements.

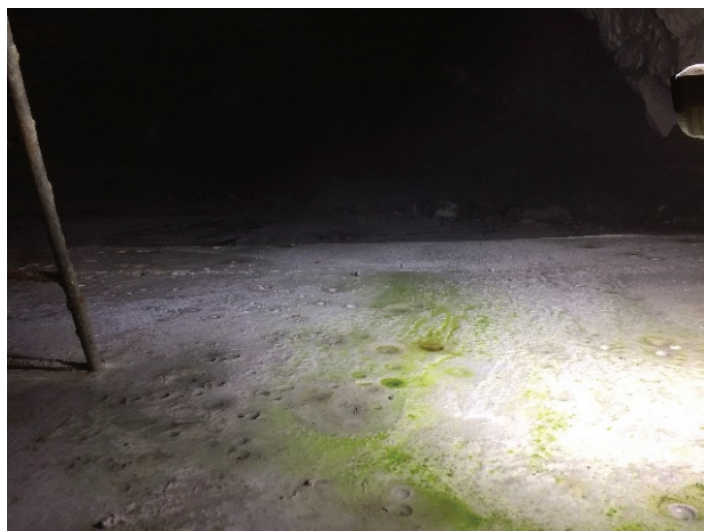

Figure 8 Paste flow performance in the goaf 


\section{$4 \quad$ TQS-FM applied to surface open pit restoration}

\subsection{Background}

With the depletion of surface accessible mineral resources, most open pit mines have been gradually changed to underground mines. Due to the lack of timely maintenance and restoration, large areas of slippage and cracking have occurred on the slopes of some of the remaining open pits (Figure 9), which can easily induce large-scale geological disasters in the long run, seriously threatening the safety of underground mining operation. However, the local prohibition on rock mining and the small production of other alternative materials makes the open pits restoration lack raw materials sources. The TQS-FM composed of HPG and tailings has the advantages of abundance and availability and has been successfully applied to open pit restoration.

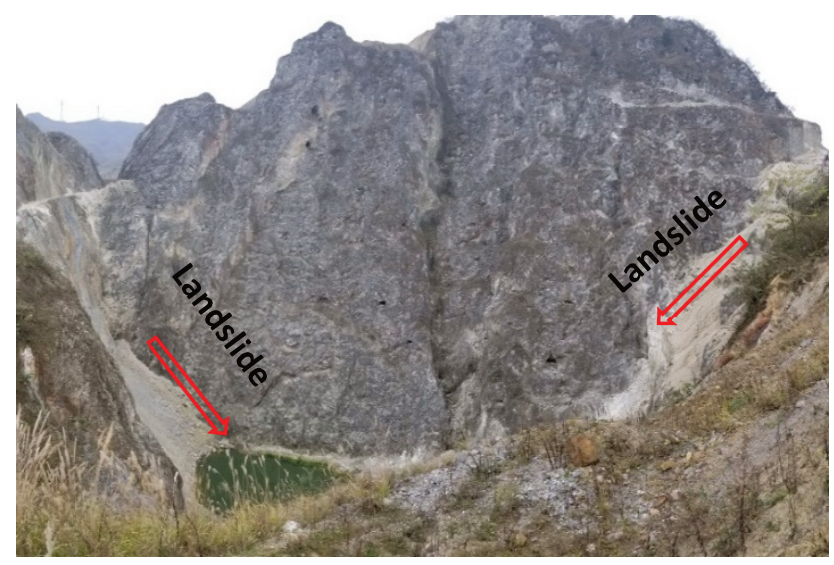

Figure 9 Several landslides in an open pit

\subsection{Key features}

\subsubsection{Preparation of high-concentration filling slurry and large-flow rate transportation}

OFB is used as a binder to prepare high-concentration filling slurry according to the formula of tailings content of $200 \%$ and concentration of $67 \%$. Both OFB and modifier are weighed by screw feeder, and tailings by belt scale. The weighed raw materials are transferred to a double-shaft horizontal mixer by a belt conveyor. The mixer with a capacity of $4 \mathrm{~m}^{3}$ operates by a working mode of continuous mixing and continuous discharging. The prepared slurry is transported to the discharge port through a slurry pump with a flow rate of $160 \mathrm{~m}^{3} / \mathrm{h}$ and a designed pipeline; it then flows to the designated filling subarea by gravity. The filling system design based on programmable logic controller has the characteristics of high automation and good stability.

\subsubsection{Partition filling in open pit}

High-concentration filling slurry has good fluidity, but will segregate during the flow leveling process. In this case, the fine particles, sludge, and organics in the slurry will gradually gather around the filter well along with the bleeding water, causing the strength of filling body in this area to decrease. The area of filling subarea $A$ and the length of slurry runoff $L$ are the key parameters of partition filling. The larger $A$ is, the slower the slurry height rises, and the safer the retaining wall is. On the contrary, the slurry height in the small subarea rises rapidly. At this time, although the slurry segregation is not significant, the partition wall with higher strength must be designed to resist lateral pressure, and the partition switching is more frequent, leading to the decrease of filling efficiency. With the increase of $L$, the slurry flow time is prolonged, and the segregation phenomenon becomes more obvious. In this case, the strength of the filling body is more uneven in the runoff direction and the surface slope is larger. In this work, the partition retaining wall is constructed by detachable light wood boards and iron triangular brackets. The lower limit of $A$ is determined according to the bond strength between the boards and the sliding resistance of the retaining wall. The upper limit of 
$A$ or $L$ is related to the maximum height difference in the runoff direction and segregation rate allowed by the design scheme. Considering the most unfavourable hydrostatic pressure condition, the $A$ and $L$ are determined as follows:

$$
\frac{10 a \cdot \rho \cdot Q \cdot T_{i}}{\sigma} \leqslant A \text { and } 2.74 Q \cdot T_{i} \cdot \sqrt{\frac{a \cdot \rho}{F_{r}}} \leqslant A
$$

where:

$$
\begin{array}{ll}
a & =\text { affluence coefficient, } 1.2 . \\
\rho & =\text { slurry density, } \mathrm{kg} / \mathrm{m}^{3} . \\
Q & =\text { filling flow rate, } \mathrm{m}^{3} / \mathrm{h} . \\
T_{\mathrm{i}} & =\text { initial setting time, } \mathrm{min} . \\
\sigma & =\text { bond strength, } \mathrm{MPa} . \\
F_{\mathrm{r}} & =\text { sliding resistance, } \mathrm{N} .
\end{array}
$$

$$
A \leqslant \frac{h_{\max } \cdot W}{i} \text { and } A \leqslant \frac{S_{\max } \cdot W}{\alpha}
$$

where:

$$
\begin{array}{ll}
h_{\max } & =\text { maximum allowable height difference, } \mathrm{m} . \\
W & =\text { width perpendicular to the runoff direction, } W<0.5 \mathrm{~L}, \mathrm{~m} . \\
i & =\text { flow slope by gravity. } \\
s_{\max } & =\text { maximum allowable segregation rate. } \\
\alpha & =\text { segregation rate per unit length, } / \mathrm{m} .
\end{array}
$$

According to Equations 7 and $8, A$ should be $900-2,000 \mathrm{~m}^{2}$, and $L$ should be less than $63 \mathrm{~m}$.

\subsubsection{Backwater of filling subarea}

In order to prevent the filling process from affecting the surrounding water and to save water resources, the filtering water and bleeding water are recycled by the leaching water collection pipe (Figure 10). The filtering water is collected into the sump through the HDPE filter pipe at the bottom of the open pit, and the bleeding water is drained into the collecting well through the soft permeable pipe with the increase in filling height. Finally, the mixed water in the sump is delivered to the surface backwater pool by a submersible pump.

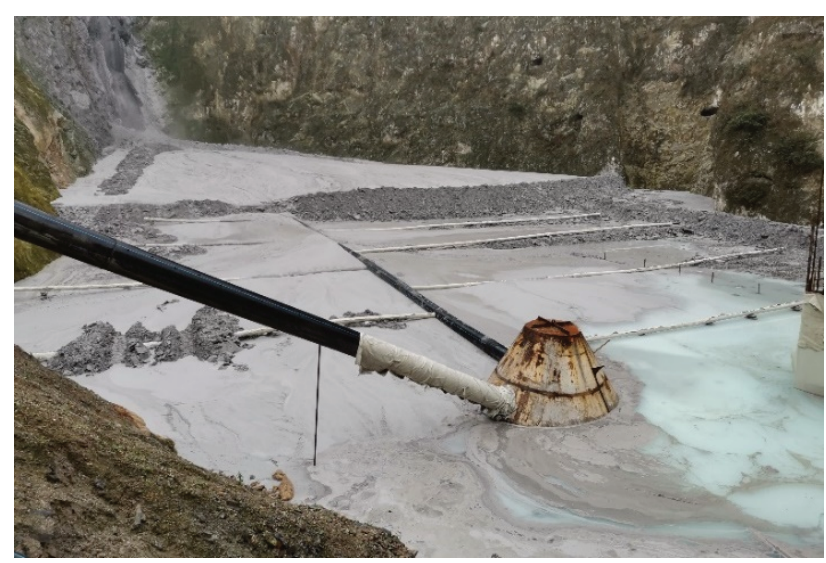

Figure 10 Arrangement of leaching water collection pipe 


\subsection{Application performance}

The high-concentration TQS-FM filling slurry has excellent leveling properties, and the surface slope of filling body in the subarea is less than 3\% (Figure 11). The strength of filling body can meet the requirements of pedestrians, laying pipes, and constructing retaining walls after curing for six hours, and is uniform in each subarea with a fluctuation of less than $20 \%\left(\mathrm{UCS}_{3 \mathrm{~d}}\right.$ 0.7-0.9 MPa). The filling process does not produce external drainage and does not affect the surrounding water. TQS-FM applied to open pit restoration not only solves the shortage of filling materials but also has a greater filling capacity and higher work efficiency than that of restoration technology based on traditional sands and gravels. In addition, compared with the uncemented sand-gravel filling body, the safety of TQS-FM filling body is significantly improved due to its high strength, good integrity, low permeability coefficient, and strong rain erosion resistance.

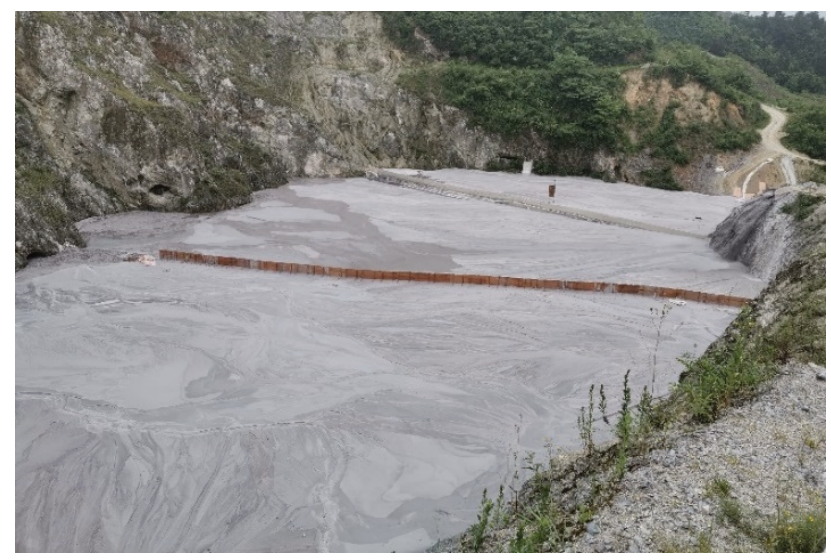

\section{Figure 11 TQS-FM applied to the open pit restoration}

\section{Conclusion}

After modifier modification and ball milling, HPG has the characteristics of quick setting (initial setting time less than $90 \mathrm{~min}$ ), high early strength (UCS3d more than $8 \mathrm{MPa}$ ), and total industrial wastes (wastes rate more than 98\%). A low-resistance, quick-setting filling material that can meet the needs of different mines can be prepared by mixing with this new binder and unclassified tailings.

The TQS-FM applied to underground goaf treatment has more advantages than cement-based pastes in terms of early strength, fluidity, material cost, and solid waste utilisation. The one-time, single-point continuous filling technology based on this material can improve the filling efficiency greatly. The comprehensive monitoring results of toxicity, harmful gas and water quality show that TQS-FM meets the strict environmental protection policy of the local government.

The TQS-FM can replace sands and gravels for open pit restoration, and the filling capacity of high-concentration filling technology based on it can reach $160 \mathrm{~m}^{3} / \mathrm{h}$. The partition filling has achieved a breakthrough of uniform strength of filling body and surface slope of less than $3 \%$ in the whole filling area of $8,000 \mathrm{~m}^{2}$. The specially designed backwater system ensures that there is no external drainage during the filling process.

\section{References}

Chen, QS, Tao, YB, Feng, Y, Zhang, QL \& Liu, YK 2021, 'Utilization of modified copper slag activated by $\mathrm{Na}_{2} \mathrm{SO}_{4}$ and CaO for unclassified lead/zinc mine tailings based cemented paste backfill', Journal of Environmental Management, vol. 290.

Jiang, GZ, Wu, AX, Wang, YM \& Lan, WT 2018, 'Low cost and high efficiency utilization of hemihydrate phosphogypsum: Used as binder to prepare filling material', Construction and Building Materials, vol. 167, pp. 263-270.

Jiang, GZ, Wu, AX, Wang, YM \& Li, JQ 2019, 'The rheological behavior of paste prepared from hemihydrate phosphogypsum and tailing', Construction and Building Materials, vol. 229, 116870.

Singh, M 2005, 'Role of phosphogypsum impurities on strength and microstructure of selenite plaster', Construction and Building Materials, vol. 19, no. 6, pp. 480-486. 
Tayibi, H, Choura, M, López, FA, Alguacil, FJ \& López-Delgado, A 2009, 'Environmental impact and management of phosphogypsum', Journal of Environmental Management, vol. 90, no. 8, pp. 2377-2386.

Wu, AX, Cheng, HY, Yang, Y \& Zhang, LF 2017a, 'Development and challenge of paste technology in China', in AX Wu \& RJ Jewell (eds), Paste 2017: Proceedings of the 20th International Seminar on Paste and Thickened Tailings, University of Science and Technology Beijing, Beijing, pp. 2-11.

Wu, AX, Lan, WT, Wang, YM, Li, ZJ, Wang, JC \& Li, JQ 2017b, 'Low cost and high strength paste filling material with solid waste', in AX Wu \& RJ Jewell (eds), Paste 2017: Proceedings of the 20th International Seminar on Paste and Thickened Tailings, University of Science and Technology Beijing, Beijing, pp. 149-154.

Xie, H \& Chen, Y 2016, 'Experimental research on creep laws of high-water material under real pressure water environment', Key Engineering Materials, vol. 705, pp. 350-354.

Yin, SH, Shao, YJ, Wu, AX, Wang, HJ, Liu, XH \& Wang, Y 2020, 'A systematic review of paste technology in metal mines for cleaner production in China', Journal of Cleaner Production, vol. 247, 119590. 
The development and practice of new quick-setting filling materials prepared by total industrial wastes

AX Wu et al. 